\title{
EUSEBIO COLOMER, HISTORIADOR DE LA FILOSOFÍA (1923-1997)
}

\author{
Eudaldo Forment \\ Universidad de Barcelona
}

\section{EL PROBLEMA DELATEÍSMO}

En el recién publicado Diccionario de Pensamiento contemporáneo, ${ }^{1}$ una de las voces monográficas, el ateísmo, se debe al profesor Eusebi Colomer. De esta monumental obra, donde se encuentran todas las tendencias y corrientes del pensamiento contemporáneo y se tratan los grandes temas debatidos en nuestro tiempo, pueden destacarse dos grandes méritos. En primer lugar, ofrece una panorámica completísima, presentada con gran rigor y con una insuperable claridad de las articulaciones del pensamiento de hoy en día.

En segundo lugar, aunque sus autores representan una adecuada selección de grandes pensadores de la actualidad, ${ }^{2}$ como ha confesado su director: «No es una obra de autor, ni corresponde tampoco a una determinada escuela o tendencia del pensamiento. Sin embargo, nuestra obra no es aséptica, pues el pensamiento nunca lo es, y, sin ser partidista, si toma partido en favor de la persona. El hilo conductor que se ha tenido presente a la hora de diseñar la obra y de coordinar a los colaboradores ha sido precisamente la persona, la defensa de su dignidad inarrebatable y la imbricación que en ella se da entre la vertiente individual y la comunitaria».3

1 Moreno Villa, M., (Dir.), Diccionario de pensantiento contemporáneo, Madrid, San Pablo, 1997, pp. 1278.

2 La redacción de las de las doscientas dieciocho voces ha corrido a cargo de ciento dieciocho especialistas en cada materia. Además de Eusebio Colomer, han intervenido: Mariano Alvarez Gómez, Luis Alvarez Munárriz, Karl-Otto Apel, Manuel Ballester Hernández, Jesús María Conill Sancho, Adela Cortina Ors, Vicente Cudeiro González, Juan Fernando Cuenca Molina, Joseph de Finance, Juan de Sahagún, Carlos Díaz, Domingo Moratalla, Enrique Dussel, Urbano Ferrer, Eudaldo Forment, Manuel García-Aldeguer, Miguel García-Baró, Jesús García López, Alfonso García Marqués, José Gómez Caffarena, José Ignacio González Faus, Lourdes Gordillo, Alain Guy, Alberto Iniesta, Pedro Lain Entralgo, José Luis López Aranguren, Pablo López López, Alfonso López Quintás, Manuel Maceiras, José M. ${ }^{a}$ Mardones, José Montoya, Mariano Moreno Villa, Ildefonso Murillo, Patricio Peñalver, Alfonso Pérez de Laborda, Angel Prior Olmos, Juan Luis Ruiz de la Peña, Lorenzo Vicente Burgoa, y José Luis Villacañas, entre otros.

3 Moreno, M., (Dir.), Diccionario de pensamiento contemporáneo, op. cit., p. 7. Precisa seguidamente Mariano Moreno, Director del Departamento de Filosofía y Sociedad del Instituto Teológico de Murcia: «Esto no significa que todos los colaboradores del diccionario entiendan a la persona en términos absolutamente idénticos» (Ibíd.). 
Estas dos cualidades de la publicación, que abre una vía de esperanza ante el futuro, son precisamente las que determinan toda la obra magisterial y escrita de Eusebio Colomer. Quedan manifestadas claramente en el extenso texto de la voz «ateísmo» del Diccionario, que podría considerarse su último trabajo publicado en vida.

Después de señalar las dificultades para encontrar una definición precisa de «ateísmo», y que: «desde el punto de vista religioso, el ateísmo práctico tiene un mayor alcance que el teórico», observa que: «Nada impide que un ateo teórico, negando explícitamente a Dios, lo afirme implícitamente en ese acto radical de libertad, por el que se compromete totalmente y elige el sentido de su vida. Como tampoco nada impide que un supuesto creyente, afirmando en teoría a Dios, lo niegue implícitamente en un acto radical de libertad de signo contrario». La razón es porque: «El verdadero lugar del hombre se halla en la encrucijada entre el bien y el mal». ${ }^{4}$

Otra importante aportación del profesor Colomer, en este estudio, es la exposición de dos caracteres nucleares del ateísmo moderno. Por una parte: «El rasgo peculiar de este ateísmo es su carácter postulatorio. Aunque mantiene, como es obvio, una verdad intelectual su raíz está en la voluntad. Como dijo Unamuno en su época: «La mayoría de nuestros ateos quieren que Dios no exista». Por otra parte, el ateísmo: «En su tremenda radicalidad, es un fenómeno poscristianom. 5

También, una vez ha expuesto la historia de los grandes ateísmos del siglo pasado -Feuerbach, Marx, Comte, Freud y Nietzsche-, y el ateísmo «humanista» - Sartre y Camusy el «científico-positivo» - Carnap y Ayer-, de primera mitad del siglo XX, comenta nuestro autor que: «Todo esto es hoy, hasta cierto punto, historia transcurrida. La crisis contemporánea de los grandes discursos afecta también a los grandes discursos ateos [...] hoy hay que considerar caducos todos los esquemas que daban por liquidado, de una vez para siempre, el problema religioso de Occidente. Si ya no es tan seguro, como pensaba el positivismo, que la ciencia alcance la realidad misma de las cosas, ya que está siempre condicionada por paradigmas históricoculturales, tampoco lo es que la fe religiosa haya de declararse en bancarrota ante la razón científica». ${ }^{6}$

En estos momentos, concluye: «La única objeción atea, que se mantiene en pie con renovado vigor, es la que se apoya en la experiencia del mal. Ante el sufrimiento de los inocentes, fracasa todo intento redondo de explicación teológica». En presencia del misterio del sufrimiento, hay que acudir a un misterio más profundo, el de Cristo. «Sólo la cruz de Cristo señala un camino para superar teológicamente el ateísmo de la protesta, pues, desde la muerte de Jesús en la cruz, el sufrimiento ya no se experimenta como algo extraño a Dios mismo». ${ }^{7} \mathrm{Al}$ interrogante sobre el sufrimiento, Dios responde desde la cruz, desde el sufrimiento unido al amor.

4 Colomer, E., Ateísmo, en Moreno, M., (Dir.), Diccionario de pensamiento contemporáneo, op. cit., pp. 102- 108, p. 103. Véase: Bilbeny, N., Filosofia contemporània a Catalunya, Barcelona, Edhasa, 1985, p. 40.

5 Ibidem, p. 104.

6 lbidem, p. 106.

7. lbidem, p. 107. 


\section{INTERÉS POR LOS DEBATES ACTUALES}

No es extraño que Colomer conociese perfectamente el ateísmo contemporáneo, «uno de los fenómenos más graves de nuestro tiempo». ${ }^{8}$ Le había dedicado ya un extenso libro. ${ }^{9}$ Además, una vertiente de su quehacer como historiador de la Filosofía, fue la de comprender en profundidad las corrientes actuales de pensamiento.

Comenzó interesándose por el gran debate de los años sesenta en torno a Teilhard de Chardin (1881-1955), el jesuita francés, famoso por su intento de exponer el cristianismo en una visión evolucionista del mundo. Concebía la evolución como un movimiento cósmico y humano hacia Cristo. Fue acusado de llegar a muchas ambigüedades, por exponer sin diferenciar claramente los planos científico, antropológico, teológico y escatólogico.

Colomer estudio principalmente la concepción teilhardiana del hombre, en el triple ámbito de la Filosofía, la Teología y la Espiritualidad. Desde la perspectiva de la antropología filosófica trató todos los temas propios del paleontólogo francés: azar y finalidad; creación y cristocentrismo; evolución y hominización; Dios Omega y Cristo Omega; socialización y personalismo, historia del mundo e historia de la salvación; dialéctica del progreso y escatología; espiritualidad de la acción y de la renuncia; y humanismo del «hacia adelante» y del «hacia arriba». Asimismo, en las varios libros que le dedicó, ofreció una visión completísima de todo el pensamiento teilhardiano de la realidad, que había examinado y valorado en sus mismas fuentes. ${ }^{10}$

En todas sus obras, Eusebio Colomer intentó mostrar que: «El 'intento' de Teilhard, prescindiendo de muchos detalles de su concreta realización, se inscribe en la línea de la mejor tradición teológica del catolicismo». Todo el «problema Teilhard» está en que: «Quiso introducir en el pensamiento cristiano el concepto moderno de evolución y buscar así un punto de inserción de la historia santa en la historia del universo. No es de extrañar que este primer intento de síntesis se haya quedado en un esbozo genial, pero incompleto»."

Manifestaba el profesor catalán que: «La originalidad de la antropología de Teilhard estriba, a mi modo de ver, en esa capacidad de abarcar el conjunto del 'fenómeno humano' en sus raíces cósmicas y en su dimensión social e histórica. El mismo problema de Dios y de la inmortalidad, central en Teilhard, se sitúa menos al nivel del hombre personal, que al de la humanidad que lucha y trabaja en la historia. En Teilhard todo es para la persona humana, pero ésta no encuentra su realización sino en la más profunda comunión del 'yo' y del 'tu', en un 'nosotros' cada vez más amplio, en cuyo horizonte, esencialmente inacabado e inacabable aquí abajo, se atisba la atracción de un hogar trascendente de comunión, un Centro de centros, infinitamente amante y amable, en el que podamos darnos y encontrarnos plenamente los unos con los otros». ${ }^{12}$

8 Gaudium et spes, 19.

9 Colomer, E., El ateísmo en nuestro tiempo, Barcelona, Nova Terra, 1967.

10 Id., Pierre Teilhard de Chardin, un evolucionisme cristia?, Barcelona, Dalmau, R., 1961; Idem, Mundo y Dios al encuentro. El evolucionismo cristiano de Teilhard de Chardin, Barcelona, Nova Terra, 1963; $2^{\mathrm{a}}$ ed., 1964; $3^{\mathrm{a}}$ ed., 1966; Idem, A evoluçao segundo Teilhard de Chardin, Porto, Tavares Martins, 1967; Idem, El pensament de Teilhard de Chardin, Barcelona, Bruguera, 1967; e Idem, Hombre y Dios al encuentro. Antropología y teología de Teilhard de Chardin, Barcelona, Herder, 1974.

11 Id., Hombre y Dios al encuentro. Antropologia y teología de Teilhard de Chardin, op. cit., p. 466.

12 Ibidem, pp. 11-12. 
En realidad, toda la preocupación de Colomer por Teilhard no debió obedecer únicamente a su permanente interés por el pensamiento contemporáneo, sino también por el problema de las relaciones entre la fe y la cultura, que en el mundo moderno y actual se ha vivido a veces de forma dramática. Profundizó en la esencia de ambas y en su relación mutua, procurando mostrar, en varios libros, que no hay contraposición entre ellas. ${ }^{13}$

En síntesis, mostraba siempre que fe y cultura son realmente distintas, pero que no debe haber una dicotomía, y menos una oposición, sino una complementariedad. No puede darse una verdadera disensión entre la fe y la cultura, porque es el mismo Dios, el que ha creado al hombre con su aptitud cultural, quien le ha revelado los misterios de la fe y le presta los auxilios necesarios para aceptarla, vivirla y desarrollarla.

\section{HISTORIA DE LA FILOSOFÍA CONTEMPORÁNEA}

En el marco de esta preocupación por el pensamiento contemporáneo, Eusebio Colomer realizó un proyecto, que ya había iniciado en su juventud, durante su época de estudio en Alemania: la publicación de una amplia historia de la filosofía alemana de Kant a Heidegger. Colomer, después de estudiar letras clásicas en Veruela (Zaragoza), y licenciarse en Filosofía y Teología en Sarriá y Sant Cugat respectivamente, hizo cursos especializados de filosofía en las prestigiosas universidades alemanas de Munich, Colonia y Friburgo de Brisgovia. Conoció personalmente y asistió a los seminarios privados de Heidegger. Tuvo también como profesores a Max Müller, Bernhard Welte, Eugen Fink, Ludwig Landgreve, Alois Dempf y Romano Guardini.

En 1964 ya había publicado una obra sobre Heidegger, ${ }^{14}$ pero fue en la década de los ochenta cuando apareció su monumental obra de historia de la filosofía contemporánea. En 1986, se publicó el primer volumen de El pensamiento alemán de Kant a Heidegger, titulado La filosofía trascendental: Kant. ${ }^{15}$ En el mismo año, también, el segundo, con el título: El idealismo Fichte, Schelling y Hegel. ${ }^{16}$ En 1990, apareció el último, El postidealismo: Kierkegaard, Feuerbach, Marx, Nietzsche, Dilthey, Husserl, Scheler, Heidegger.17

Este extenso y objetivo trabajo de investigación lo había sentido como una obligación intelectual. Para comprender en lo posible el mundo actual y ayudar a hacerlo a otros, era preciso dedicarle todos sus esfuerzos, porque: «A partir de Kant, la gran filosofía europea empieza a hablar alemán. La serie imponente de grandes filósofos que se suceden casi sin solución de continuidad por

13 Id., Hombre e historia, Barcelona, Herder, 1962; Idem, Església en diàleg, Barcelona, Nova Terra, 1967; Idem, Iglesia en diálogo, Barcelona, Nova Terra, 1969; Idem, Déu viu o mort? Una aproximació històrico.crítica a la teología radical, Barcelona, Nova Terra, 1970; Dios no puede morir. Una aproximación histórico-crítica a la teología radical, Barcelona, Nova Terra, 1970; e Idem, A morte de Deus, Porto, Tavares Martins, 1972.

14 Id., Heidegger: Pensament i poesia en l'absència de Déu. Assaig preliminar i selecció de textos, Barcelona, Estela, 1964.

15 Id., El pensamiento alemán de Kabnt a Heidegger. I. La filosofia trascendental: Kant, Barcelona, Herder, 1986; $2^{\mathrm{a}}$ ed. 1993.

16 Ibid., o. c. II. El idealismo: Fichte, Schelling y Hegel, Barcelona, Herder, 1986.

17 Ibid., o. c. III. El postidealismo: Kierkegaard, Feuerbach, Marx, Nietzsche, Dilthey, Husserl, Scheler, Heidegger, Barcelona, Herder, 1990. 
espacio de más de siglo y medio, desde Kant, Fichte, Schelling, Hegel, Kierkegaard, Marx, Nietzsche hasta Dilthey, Husserl y Heidegger, constituye un fenómeno único en la historia europea. Aquí y no en otra parte, por obra de pensadores originales y creadores y no de meros epígonos, se plantean y resuelven para bien o para mal los grandes problemas espirituales, sociales y políticos de la época moderna». De tal manera, concluye, que: «Todavía hoy, si queremos comprender verdaderamente lo que nos pasa, si queremos saber lo que culturalmente somos, de dónde venimos y adónde vamos, hay que acudir a su obra de pensamiento». ${ }^{18}$

Las características comunes de cada uno de los cuidados estudios de los doce autores, analizados minuciosamente por Colomer, podrían ser, en primer lugar, la completa y suficiente exposición sintética del pensamiento filosófico de cada uno de ellos, basada en uso directo de las fuentes. En todos ellos, siempre deja hablar al autor. La segunda sería que siempre se tienen en cuenta las principales interpretaciones, especialmente las más recientes, procurándose aunarlas en una visión coherente y convincente. Por último, como tercera cualidad de su metodología, habría que citar su comprensiva y respetuosa valoración de cada una de los filósofos y de sus distintas doctrinas.

Respecto a esta última peculiaridad, se ha dicho que: «Eusebi Colomer no ha querido poner su estudio al servicio de ninguna tesis personal o de escuela, sino que quiere 'ver' a cada pensador en su radical autenticidad y en el proceso que lo enlaza genéticamente con los predecesores y lo abre a los posteriores. Nuestro autor, pues, no sólo historia un periodo, sino que 'ofrece' lúcidamente al filósofo presentado en toda la vital riqueza de su camino de pensamiento, en función del respeto que le merece toda creación filosófica. A este fin ordena su discurso a una exigencia de objetividad asintótica, es decir, la que aspira a captar las líneas maestras de los filósofos estudiados en un proceso inevitablemente sin fin». ${ }^{19}$

Además de la objetividad de la hermenéutica de Colomer, hay que destacar su actitud dialogante. En sus obras, la historia de la filosofía se hace diálogo, coloquio. En este diálogo se adivina la corrección y hasta la estima por el texto, al que se ha acercado previamente y ha procurado escuchar, para compartir la problemática que presenta y comprender su respuesta. Eusebi Colomer es un historiador dialogante.

Quizá donde es más patente su posición, en la que no hay lugar para la condena apriorística y sí, en cambio, para la recepción y la comprensión, es en las más de doscientas páginas dedicadas a Heidegger. Su «magno esfuerzo de clarificación» ${ }^{20}$ de un pensamiento dificilísimo se revela sobre todo en el planteamiento y la solución del problema de Dios del filósofo alemán.

Prueba Colomer que: «Ante la cuestión de Dios, Heidegger se mantiene en una espera callada y respetuosa, como una disposición para el acogimiento de su futura venida. Hoy por hoy la misma pregunta: ¿quién es el Dios? le parece 'demasiado difícil para el hombre y planteada demasiado pronto'». ${ }^{21}$. Todavía dejó más clarificada la posición de Heidegger en el estudio posterior La qüestio de Déu en el pensament de Martín Heidegger. ${ }^{22}$

18 Ibid., o. c. I. La filosofia trascendental: Kant, op. cit., p. 1.

19 Badia, A., «La filosofía no ha muerto», en La Vanguardia, Barcelona, (11-IX-1990), p. 17.

20 Ibid., o. c. p. 17.

21 Colomer, E., El pensamiento alemán de Kant a Heidegger. III. El postidealismo: Kierkegaard, Feuerbach, Marx, Nietzsche, Dilthey; Husserl, Scheler, Heidegger; op. cit., p. 626.

22 Id., La qüestio de Déu en el pensament de Martín Heidegger, Barcelona, Facultat de Teologia, 1990. 
Con la misma diafanidad y profundidad, Colomer expone la doctrina del ser de Heidegger y especialmente la cuestión de la denominada «diferencia ontológica». ${ }^{23}$ Considera que: «A él corresponde el mérito de haber devuelto actualidad a la vieja cuestión del ser, por mucho que no haya sido capaz de darle una respuesta satisfactoria. De hecho, en su pensamiento abundan más las preguntas que las respuestas».

Advierte, también que, en su ontología, no hay lugar para el preguntar sobre lo fáctico, lo que existe. «Una ontología neutra y formal como la suya significa la muerte de la auténtica metafísica, que exige siempre decisión, toma de posición»». ${ }^{24}$ Parece que «ha olvidado abiertamente la cuestión del ente».

Considera también que en la ontología heideggeriana se da el olvido del otro como otro y, por consiguiente, de la ética. Afirma Colomer que: «El hombre no es sólo un ente cuya tarea consiste en encontrar el sentido del ser, velado por la historia de la metafísica, sino también alguien, cuyo sentido se encuentra concretamente en la relación con el otro. Y es también en la experiencia del rostro del otro, como subraya Levinas, donde el hombre lee la huella del rostro de Dios». ${ }^{25}$

\section{HISTORIA DE LA FILOSOFÍA DEL RENACIMIENTO}

El interés de Eusebio Colomer no era sólo por el presente y su proyección futura, sino también por el pasado, por el patrimonio que nos ha transmitido, para desarrollarlo e incrementarlo. «La historia de la cultura - escribe- es siempre la historia de un encuentro, en el que se da, transformado, a los que vienen lo que se recibió de los que ya se fueron. La filosofía, pese a las características especiales que la distinguen de las otras ramas del árbol del saber humano, no constituye en ello ninguna excepción. Las ideas filosóficas no nacen por generación espontánea, a la buena de Dios o en la mente de individuos aislados, sino que son el fruto sazonado de semillas de pensamiento lanzadas, lustros y a veces hasta siglos atrás, en el terruño de la historia». ${ }^{26}$

La otra vertiente de su tarea filosófica fue el estudio histórico y temático del pensamiento medieval y renacentista. En 1973, Colomer publicó un importante libro sobre Ramón Llull, Nicolás de Cusa y Juan Pico della Mirandola, De la Edad Media al Renacimiento.

En esta conocida y apreciada obra con el intento de evidenciar con datos históricos: «Cómo una serie de concepciones en tomo a Dios, al mundo y al hombre y a la idea metafísica del Dios-hombre, Jesucristo, como lazo de unión entre el Creador y la creación, han pasado, no sin sufrir importantes variaciones, del pensador catalán al alemán y de éste al italiano. Es como una vieja melodía, cuyos temas fundamentales se repiten una y otra vez y se enriquecen con nuevos matices». ${ }^{27}$

23 Ibid., o. c., El pensamiento alemán de Kant a Heidegger. III. El postidealismo: Kierkegaard, Feuerbach, Marx, Nietzsche, Dilthey, Husserl, Scheler, Heidegger, op. cit., pp. 558 y ss.

24 Ibid., o. c., p. 642.

25 Ibid., o. c. p. 643.

26 Id., De la Edad Media al Renacimiento. Ramón Lull, Nicolás de Cusa y Juan Pico della Mirandola, Barcelona, Editorial Herder, 1975, p. 11. Añade: «Sin pretender negar ni disminuir en nada la parte esencial, que en la marcha de las ideas corresponde al genio y al esfuerzo creador de los grandes pensadores, es un hecho que en el caso de la filosofía se cumple también a su modo el dicho evangélico de que uno es el que siembra y otro el que siega» (Ibid.).

27 Ibid., pp.11-12. 
Los descubrimientos de estas investigaciones históricas de Eusebio Colomer son importantísimos. Como ha escrito el historiador Gonzalo Díaz: «El estudio de los orígenes del lulismo del Cusano le llevó a descubrir como mediador entre ambos al maestro flamenco Heimeric van den Velde o de Campo. De este modo Colomer establecía históricamente que la fuente del lulismo del famoso cardenal germano se encontraba en París, concretamente en torno a la vieja cartuja de Vauvert y su rica colección de manuscritos lulianos, y no en los círculos lulistas de Padua 0 en general de Italia».

También indica, el eminente historiador de la filosofía española, que Colomer: «Posteriormente mostró como una serie de temas lulianos, en concreto una determinada concepción de Dios, del mundo y del hombre y la 'idea' metafísica del Dios-Hombre, Jesucristo, como lazo de unión entre el Creador y la creación, pasaron, no sin sufrir importantes variaciones, del pensador catalán, al alemán y al italiano». ${ }^{28}$

En Movimientos de renovación: Humanismo y Renacimiento, ${ }^{29}$ uno de sus últimos libros, que apareció a mediados de 1997, Colomer continua el estudio del Renacimiento y de su Humanismo, presentando una visión completa y detallada de este movimiento, que se extendió por toda Europa. Ha tenido el acierto de estudiarlo tanto en su desarrollo histórico, examinando el pensamiento de sus grandes autores, como en sus temas esenciales: individuo, cosmos y ciudad.

Hay que destacar de este nuevo libro, además de su interesante y amena exposición, las muchas y sugerentes observaciones sobre los autores, sus obras y todo el movimiento renacentista en general. Entre ellas, la negación de la contraposición entre Edad Media y Renacimiento, si se advierte que: «En la afirmación gozosa del mundo de la espiritualidad franciscàna, en el giro hacia la interioridad de la mística tardomedieval y en el interés nominalista por la realidad concreta e individual (están) los primeros gérmenes del descubrimiento renacentista del hombre y del mundo». ${ }^{30}$

Igualmente confirman esta sugerente tesis los: «Dos caracteres peculiares del movimiento humanista: el cultivo de la historicidad y de la humanidad. También la Edad Media había cultivado a su modo la sabiduría clásica. Si lo propio del Renacimiento hubiera sido únicamente la vuelta a la Antiguiedad, entonces la entera Edad Media se convertiría en una serie de sucesivos renacimientos. El humanismo renacentista no se define sólo por el amor y el estudio de la sabiduría clásica, sino por su voluntad de restaurarla en su forma auténtica, de entenderla en su realidad histórica». ${ }^{31}$

En este momento cultural, explica Colomer: «Los autores griegos y latinos se convierten en modelos insuperables de las litterae humanae, o sea, de las disciplinas que se cultivaban en los studia humanitatis y, por consiguiente, en auténticos maestros de humanidad» $3{ }^{32}$ Estos estudios tenían por objeto lo más propio, específico y elevado, que crea el hombre - la gramática, la retórica, la poesía, la historia y la filosofía y, por consiguiente, se consideraba también, que eran lo más adecuado para su formación como hombre.

28 Diaz, G., Hombres y documentos de la Filosofía española, $C-D$, Madrid, Consejo Superior de Investigaciones Científicas, 1983, vol. II, voz «Colomer Pous, Eusebio», pp. 364-366, p. 365.

29 Colomer, E., , Movimientos de renovación. Humanismo y Renacimiento, Akal, Madrid; 1997.

30 Ibid., o.c. p. 7.

31 Ibid., o.c. p. 10.

32 Ibid., o.c. p. 9. 
Concluye, Colomer, que: «El humanismo nació, pues, en los studis humanitatis, lo que significa que fue primordialmente un movimiento de carácter más bien erudito y literario que filosófico. Ello no quiere decir que el Humanismo no ejerciera después una profunda y decisiva influencia en el desarrollo de la filosofía. La ejerció, sin duda alguna. Más aún, insensiblemente, pero de una forma cada vez más dẹcidida, el humanismo desembocó en la filosofía». ${ }^{33}$

Para nuestro autor, el común denominador de todas figuras renacentistas, que ha estudiado, es el humanismo, en este último sentido. En todas ellas, se encuentra: «El interés por los problemas morales y humanos y la afirmación del valor y la dignidad del hombre y de su lugar primacial en el seno del universo». ${ }^{34}$

Entre otras importantes observaciones, pueden citarse las que se encuentran en las páginas dedicadas al dominico Giordano Bruno, condenado por herético por la Inquisición, como recuerda la famosa estatua de Campo di Fiori en Roma, plaza en que fue quemado vivo, el 17 de febrero de 1600. Bruno, explica: «Recondujo la magia renacentista a sus fuentes paganas y consideró que la religión mágica egipcia era una experiencia teúrgica y extática genuinamente neoplatónica, a través de la cual podían alcanzarse las ideas divinas, el sol inteligible, el uno del neoplatonismo. En este sentido, Bruno es un mago hermético del tipo más radical, que utiliza el aparato conceptual del neoplatonismo, heredado de Plotino y del Cusano, para construir una especie de gnosis renacentista, una religión de la naturaleza, llamada a reemplazar al para él trasnochado y antinatural sobrenaturalismo cristiano».3.

Tiene igualmente un gran interés la sugerente lectura que hace de Erasmo de Rotterdam. Para el Dr. Colomer: «Si su intento de actualizar la philosophia Christi con las armas conjuntas de los filósofos griegos y de los Padres de la Iglesia puede ser objeto de discusión, su sinceridad religiosa está fuera de toda duda. Erasmo luchó por un cristianismo restituido a la pureza de sus fuentes neotestamentarias, que él mismo se encargó de editar, abierto a todos y convertido en sustancia de la vida humana».

Según su interpretación: «Erasmo, más que ideas y conceptos, expone talantes y actitudes espirituales. Este es el caso del Enchiridion militis Christiani, auténtico manifiesto de cristianismo interior, suave y tolerante, y del célebre Moriae encomium [...] Una vez estallada la reforma, a la que había preparado el terreno con su crítica de los usos y abusos eclesiásticos, Erasmo opone en el De libero arbitrio un sí inequívoco, a la vez humanista y católico, a la negación luterana de la libertad del querer. Hubo de ser duro para él, hombre del compromiso y de la conciliación, tener que tomar finalmente partido. De hecho Erasmo lo tomó en favor de la vieja Iglesia y contra el luteranismo, sin renunciar empero a sus convicciones más arraigadas». ${ }^{36}$

33 Ibid., o. c. pp. 9-10.

34 Ibid., o.c. p. 10.

35 Ibid., o. c. p. 42. Indica Colomer que: «De todos los pensadores italianos del Renacimiento ninguno ha sido objeto de enjuiciamientos tan dispares como Bruno. Mientras que el confidente de Descartes y Galileo, M.. Mersenne, lo llamó uno de los hombres más malvados que jamás haya pisado la tierra, la historiografía italiana de la época del Rissorgimento lo presentó comó martir de la libertád de conciencia y heraldo de la ciencia y del pensamiento modernos. Lo primero es desgraciadamente verdadero, por muy cierto que sea que, en su decidida militancia anticristaina, Bruno había dejado atrás la misma herejía. Lo segundo es en parte una leyenda que el mismo contribuyó a forjar» (Ibid.).

36 Ibid., p. 39. Observa, no obstante que: «En Erasmo repercuten todas las contradicciones de su atormentada época. Estas, resueltas sólo en su espíritu, acabaron arrollándolo» (Ibid.). 


\section{LA EDAD MEDIA: RAMON LLULL}

El interés de Eusebio Colomer por la filosofía de la Edad Media y su proyección en el Renacimiento, obedecía a otro más concreto: Ramón Llull. En una de sus obras dedicadas a la historia medieval y renacentista confiesa: «Estos estudios han nacido de mi interés por la figura de Ramón Llull. Fue su relación con el pensamiento de Llull lo que me llevó a estudiar el pensamiento de Nicolás de Cusa y de Pico de la Mirandola. El viejo maestro catalán es mucho más que el creador de una lengua literaria y el primer representante de lo que lüego se llamará la mística hispana: es también uno de los pocos pensadores de nuestro país que han tenido auténtica proyección europea». ${ }^{37}$

En su último libro, que apareció también a mediados de 1997, El pensament als Països Catalans durant l'Edat Mitjana i el Renaixement, ${ }^{38}$ donde estudia, a la luz del estado actual de las investigaciones históricas, las doctrinas de Ramon Llull, Ramon Martí, Arnau de Vilanova, Sibiuda, Turmeda y Vives, dedica más de la mitad de la obra al primero. Para Colomer, se justifica, porque considera que: «Ramon Llull es uno de los pensadores mas originales, unitarios y polifacéticos de la Edad Media. Aunque su pensamiento está muy lejos de agotarse con la invención del 'Arte general', éste es, sin duda, el aspecto que le ha dado mas celebridad. En el origen del (Arte) hay una finalidad apologética. Convencido Llull de la unidad de la verdad, concibe su pensamiento como un método racional de demostración de las verdades de la fe cristiana». ${ }^{39}$

Llull no separa la Filosofía de la Teología, sino que las implica de un modo circular. Ya había escrito Colomer que: «Los caminos lulianos hacia Dios se mueven en el horizonte de la fe cristiana conforme al conocido axioma anselmiano: Fides quarens intellectum [...] Lo primero que exige Llull al que quiere elevarse por la razón al conocimiento de Dios es que crea previamente en El. En este sentido Llull no hace ninguna distinción entre las verdades accesibles a la sola razón natural, como, por ejemplo, la existencia y atributos esenciales de Dios, y las verdades inaccesibles a la sola razón, como, por ejemplo, el misterio de la Santísima Trinidad. Tan posible es al entendimiento humano entender la unidad como la Trinidad de Dios, pero en ambos casos se prerrequiere la luz de la fe»s..$^{40}$

En el pensamiento luliano, no se da una reducción de la fe a la filosofía. «Llull está tan lejos aquí de mostrarse un racionalista, que más bien nos parecería un fideísta. En realidad, interpretado en su contexto histórico, maestro Ramón no es ni una cosa ni otra, sino un 'retrasado' cultural, que en una época en la que Tomás de Aquino había replanteado sobre nuevas bases el viejo problema de las relaciones entre la fe y la razón, se mueve todavía en el horizonte teológico del agustinismo». ${ }^{41}$

37 Colomer, E., , De la Edad Media al Renacimiento. Ramón Lull, Nicolás de Cusa y Juan Pico della Mirandola, op. cit., p. 13

38 Id. El pensament als Països Catalans durant l'Edat Mitjana $i$ el Renaixement, Barcelona, Institut d'Estudis Catalans i Publicacions de l'Abadia de Montserrat, 1997.

39. Ibid. p. 19.

40 Id. De la Edad Media al Renacimiento. Ramón Lull, Nicolás de Cusa y Juan Pico della Mirandola, op. cit., pp. $62-63$.

41 Ibid., o. c. p. 64. 
Desde su convicción de la unidad de la verdad cristiana: «No se trata, pues, en Llull de sustituir la razón por la fe, ni la fe por la razón, sino de utilizarlas a ambas en el común ideal de la sapientia cristiana». ${ }^{42}$ De manera que: «Del pensamiento luliano como el agustiniano cabe, pues, afirmar que ni siquiera en el conocimiento de la existencia de Dios escapa al credo ut intelligam. Y ello no por desprecio de la razón, sino por aprecio de la fe». ${ }^{43}$

En sus estudios, Colomer ha mostrado que: «El pensamiento de Ramón Llull constituye una grandiosa metafị́sica descendente, cuya vinculación a la corriente del platonismo cristiano, que por la doble vía dé.Porfirio y Agustín, Proclo y el Pseudo-Dionisio Areopagita fecunda toda la Edad Media». ${ }^{4}$

Además, también ha hecho notar que: «Pocos sistemas medievales se han acercado tanto como el de Llull al idẹal platónico y hegeliano de una lógica, que sea a la vez ontología. Y no puede ser de otro modo, puesto que el orden del ser y el orden del pensar se encuentran en Dios, en cuyo pensamiento infinito la realidad es precontenida en la idea. De aquí que esta onto-logía luliana sea esencialmente teo-logía, con lo que el pensamiento de Llull adquiere plenamente aquella estructura onto-teo-lógica; que ha sido señalada con razón como característica de la metafísica». ${ }^{45}$

Desde su peculiar metafísica ejemplarista y, por ello: «Tomando como punto de partida un concepto ejemplarista, más o menos platonizante de Dios, Llull busca llevar a todo el mundo al reconocimiento de los dos misterios cristianos de la Trinidad y de la Encarnación. Este intento de probar la verdad de la fe cristiana por razones necesarias le valdrá más tarde la acusación de heterodoxia». ${ }^{46}$

No obstante, Llull, como advierte seguidamente Colomer: «Se movía en el horizonte mental de los grandes autóres latinos del siglo XII, concretamente de San Anselmo y de los victorinos, los cuales no distinguèn todavía, como lo hará Santo Tomás de Aquino, entre las verdades religiosas abiertas a la razọn y las accesibles sólo a la fe, sino que, de acuerdo con el conocido lema anselmiano según el cual la fe busca la inteligencia (fides quaerens intellectum), buscaban entender lo que creían y asociaban un inequívoco optimismo racional a la afirmación agustiniana de la primacía de la fe». ${ }^{47}$

Reconoce, en definitiva, que: «Ramón Llull naufragó necesariamente ante una tarea enorme que superaba las fuerzas de un sólo hombre. Pero sus ideales de universalidad de la fe, del saber y de la misma sociedad humana son hoy más válidos y urgentes que nunca y permanecen abiertos a la humanidad de todos los tiempos como una llamada a la acción». ${ }^{48}$ Concluye finalmente que: «Sean cuales sean sus incoherencias doctrinales y sus inconsecuencias prácticas, Ramon Llull tiene el derecho de pasar a la historia como un hombre que puso la fuerza de la verdad por encima de la violencia». ${ }^{49}$

42 Ibid., o. c. pp. 65-66. «Llull insistirá en la necesidad de esa colaboración entre fe y razón frente a la actitud contraria de una filosofía autónoma, que él ve encarnada en los averroístas, quienes sólo prescinden de la fe a costa de graves errores» (Ibid., p. 66, nota 31).

43 Ibid., o. c. p. 65.

44 Ibid., o.c. p. 56.

45 Ibid., o. c. p. 57.

46 Id. ,El pensament als Països Catalans durant l'Edat Mitjana i el Renaixement, op. cit., p. 20.

47 Ibid., pp. 20-21.

48 Id. , De la Edad Media al Renacimiento. Ramón Lull, Nicolás de Cusa y Juan Pico della Mirandola, op. cit., p. 43.

49 Id. , El pensament als Països Catalans durant l'Edat Mitjana i el Renaixement, op. cit., p. 178. 


\section{LA FILOSOFIA CATALANA MEDIEVAL Y RENACENTISTA}

El profesor Colomer no se limitó a estudiar la doctrina de Llull, su interés por el pensador mallorquín se amplió al de los autores que le siguieron directamente o bien que se mantuvieron en su actitud filosófica y teológica tradicional respecto a las relaciones entre razón y fe. Precisamente: «La originalidad de Llull radica en el hecho que lleva esta tendencia hasta el extremo, en el mismo momento en que su influencia histórica comenzaba a declinar. Por decirlo de una manera drástica: si Llull resulta nuevo en su época, es porque es literalmente anacrónico. El defendió aferradamente el viejo ideal agustiniano de la sabiduría cristiana, cuando todo el mundo la había abandonado». ${ }^{50}$

En El pensament als Països Catalans durant l'Edat Mitjana i el Renaixement, además de la de Llull, se examinan las doctrinas del dominico catalán Ramón Martí, discípulo de San Alberto Magno y condiscípulo de Santo Tomás, y de su discípulo el médico valenciano Arnau de Vilanova, seguidor del movimiento reformista de los «Espirituales», surgido en el franciscanismo.

Respecto al primero, nota su cambio de posición para adoptar el nuevo camino de Santo Tomás, que fue en líneas generales el que siguió el pensamiento cristiano. Sin embargo: «El pensamiento de Martí dista mucho de la originalidad y de la coherencia cerrada del de Llull. Este le supera con creces tanto por la capacidad especulativa como por la cualidad literaria y humana». ${ }^{51}$ Asimismo, también según Colomer: «Se busca hoy una unidad de filosofía y teología, de teología fundamental y dogmática, de fundamentación de la fe y de reflexión sobre su contenido, que recuerda en cierto sentido el que, a su manera, hizo Llulls. ${ }^{52}$

Al inquieto Arnau de Vilanova le dedica, en este libro, un interesante capítulo. Colomer lo había estudiado recientemente. A él le consagró su último cursillo en la Fundación Balmesiana, que tituló Aproximación a Arnau de Vilanova (1240-1311). Lo dictó en tres sesiones, los días 6, 13 y 20 de marzo de 1996. En la primera, Perfil biográfico: del médico escolástico al polemista antiescolástico, dio un esbozo de una imagen fiable de Arnau, en su doble faceta médica y espiritual, sobre el fondo de una época atravesada por una de las crisis más profundas de la cristiandad medieval.

En la segunda, Las bases antropológicas de un proyecto espiritual, indicó que Arnau ha pasado sobre todo a la historia por su profetismo escatológico. Sin embargo, demostró que el verdadero eje de su pensamiento espiritual no es el anuncio profético-apocalíptico, sino un proyecto de reforma evangélica y, en función de éste, el esbozo de una antropología de cariz espiritualista, donde traza la fisonomía dèl hombre llegado a ser ángel.

La tercera y última, De la cábala hebrea a la càbala cristiana, fue una brillante e interesante exposición de la exégesis arnaldiana del nombre innominable. Comentó la célebre Allocutio super significationem nominis Tetragrammaton, donde Arnau interpreta en sentido trinitario el tetragra-

50 Ibid, o. c., p. 237. Véase: Alain Guy, Historia de la Filosofia Española, Barcelona, Anthropos, 1985, pp. 470-472.

51 Ibid., o. c., p. 238

52 Ibid., o. c., p. 238, nota 207. 
ma hebreo: Jahvé y presenta ahora los dos monogramas latinos: Jesus y Christus con un nuevo tetragrama cristiano. ${ }^{53}$

Los estudios de los humanistas catalanes - el lulista barcelonés Ramón Sibiuda, rector de la Universidad de Toulouse, el franciscano mallorquín apóstata Anselmo Turmeda, y Luis Vives, el humanista valenciano tan admirado por Melchor Cano--, que también se encuentran esta obra de Colomer, tienen igualmente gran interés. En realidad, vienen a confirmar la tesis de José Torras y Bages de que en Cataluña pervivió el espíritu medieval y no se dio en sentido estricto el del Renacimiento.

Según el tomista catalán, los pensadores de este momento histórico: «Son vehementes sostenedores del antiguo orden de cosas, de más humildes apariencias, pero de mayor solidez y bondad que la nueva manera». ${ }^{54}$ El Renacimiento - afirmaba - fue «Una era nueva, y siendo el capital intelectual substancialmente el mismo, hace su curso desviándose del camino llano y popular, y aparece una nueva forma más correcta, más señora, más exquisita, pero que elevando el pasto intelectual, lo hace menos asequible a la generalidad de los hombres». ${ }^{55}$

A diferencia de la Edad Media, el Renacimiento no tuvo ni el origen ni el carácter popular. «El Renacimiento fue una revolución aristocrática hecha en detrimento de los pueblos, y entre todos estos el catalán, que, poi una admirable precocidad, había llegado a un extraordinario desarrollo del espíritu, fue la víctima más sacrificada ${ }^{56}$ Claramente se advierte en el arte. «El Renacimiento [...] dio el golpe de muerte a la literatura catalana; ésta estaba informada por el espíritu popular, y la nueva moda buscaba una literatura oficial y cortesana, tenía un gusto aristocrático, despreciaba tanto a la filosofía como el arte literario, y el arquitectónico, y hasta el gobierno político, de la Edad Media». ${ }^{57}$

Sobre todos estos autores, Eusebi Colomer había escrito muchos artículos, ${ }^{58}$ presentado varias ponencias en congresos nacionales e internacionales, ${ }^{59}$ a los que había sido invitado, e impartido muchísimas conferencias, cursillos y cursos.

53 El Dr. Colomer colaboraba con el Instituto Filosófico de la Fundación Balmesiana desde el curso académico 1959-1960, en el que intervinó en un cursillo sobre cuestiones particulares de filosofía con Luis Cuéllar, Joaquín Aragó y Jaime Bofill. Véase: Forment, E., «El Instituto Filosófico de Balmesiana y la revista Espíritu», en Antonio Heredia Soriano, Actas del VI Seminario de Historia de la Filosofia Española e Iberoamericana, Salamanca, Ediciones Universidad de Salamanca, 1990, pp. 167- 184. Una de sus mejores intervenciones en Balmesiana fue la presentación de la obra de Francisco Canals Vidal, Sobre la esencia del conocimiento, Barcelona, PPU, 1987 que tuvo lugar en el salón de actos de la institución el día 3 de octubre de 1987. Véase, Colomer, E., «Entorn del llibre de F. Canals Vidal: 'Sobre la esencia del conocimiento'», en Espíritu, Barcelona, 97 (1987), pp. 64-78.

54 Torras I Bages, J., La Tradició catalana, en Obres Completes, vol. I-VIII: Barcelona, Ed. Ibèrica, 1913-1915; y vol. IXy X: Barcelona, Foment de Pietat Catalana, 1925 y 1927 , vol. IV, 1913, p. 295.

55 Ibíd., o. c., p. 388.

56 Ibid., 0. c., p. 399.

57 Ibíd.,. o. c., pp. 306-307.

58 Publicó más de ciento cincuenta artículos en las principales revistas de Filosofía. Véase: Borras, A., Sola, F. de P., y Torrello, J.M. , Escipitors jesuittes de Catalunya. Bibliografia 1931-1976, Barcelona, S. Cugat, 1979, pp.103-110.

59 Intervino en los Congresos Internacionales de Filosofía medieval de Colonia (1961), Passo della Mendola (1964), Montreal (1967), Madrid (1972), Bonn (1977); en los internacionales de Filosofía de Viena (1968) y Varna (1973); internacionales lulianos de Formentor (1960) y Miramar (1976); congresos tomistas de Roma (1965 y 1980); y los congresos «Teoría y Praxis» de Génova-Barcelona y «Metafísica y ciencias del hombre» de Bérgamo (1976 y 1980).Participó en las conmemoraciones centenarias de G. Pico della Mirandola en Città della Mirandola (1963) y de Nicolás de Cusa en Bernkastel-Kues-Bressanone (1964). También, en las reuriones medievales de Colonia (1960, 1962 y 1965) y los simposios cusianos de Tréveris $(1973,1977$ y 1982), y en otras muchas reuniones nacionales e internacionales. 


\section{LA ÚLTIMA LECCIÓN}

La relación de Eusebio Colomer con Ramon Llull fue tan estrecha y especial, que misteriosamente murió el día de la fiesta del beato, el 27 de noviembre, en una mesa redonda dedicada al pensamiento luliano y cuando estaba hablando de él. Murió en su lugar preferido, la universidad, entre sus alumnos y compañeros, y disertando sobre Ramon Llull. Siempre se había dedicado a la enseñanza universitaria, dividía el curso académico entre la Facultad Eclesiástica de Filosofía de Cataluña y la Facultad civil de Filosofía de la Universidad de Deusto. En la actualidad era profesor de Filosofía en la Facultad de Filosofía, de la Universitat Ramon Llull, y de la Facultad de Teología de Cataluña. ${ }^{60}$

Eusebi Colomer nació en Girona, el 14 de abril de1923. Hizo los estudios primarios con los Hermanos de las Escuelas Cristianas, y el bachillerato en el Instituto de Segunda enseñanza de Gerona. El 19 de marzo de 1941 ingresó en la Compañía de Jesús en Veruela ${ }^{61}$ Fue ordenado sacerdote con ocasión del Congreso eucarístico Internacional de Barcelona de 1952, el día 13 de abril. Se doctoró en filosofía, en la Universidad de Colonia, sobre un tema que le introdujo en uno de sus campos de investigación, Ramon Llull y la historia del lulismo. Su tesis doctoral, Nikolaus von Kues und Raimund Llull. Studien aus Handschrifften der Kueser Bibliothek, defendida en 1957, se publicó pocos después en Alemania. ${ }^{62}$

El profesor Francesc Torralba narró de este modo el fallecimiento repentino de Colomer, en una sala de conferencias de la Facultad de Filosofía de la Universitat Ramon Llull, en un acto académico dedicado a Doctor Iluminado, en el día de su festividad: «Era una mañana del mes de noviembre, una mañana fría, pero nítida y clara. El día amaneció con una perfecta transparencia mediterránea. Era el día del beato Ramón Llull, una fecha llena de premonición simbólica».

Se explica en este artículo, titulado Colomer: el ejercicio de la sabiduría, que: «Después de las palabras del ponente, Colomer rompió el silencio con su elegancia moral, tan patente en sus intervenciones académicas. Elogió la forma de la ponencia y se dispuso a precisar algunas cuestiones desde su humilde talante. Pero esa mañana de noviembre, Colomer se sentía cansado y su voz no fluía tan fuerte y tenaz como era habitual en él, sino más bien tenue y débil. Nos ilustró a todos los oyentes con unas palabras sobre Ramón Llull, sobre la herencia histórica del (Ars) luliana en el Renacimiento y en la modernidad, tema que conocía perfectamente». En estos momentos, explica el testigo de estos últimos momentos de Eusebio Colomer: «La muerte, intrusa y siempre inoportuna, irrumpió violentamente en la sala y Colomer dejo de hablar para siempre». ${ }^{63}$

60 También había sido profesor en la Facultad de Filosofía de la Universidad Católica de Braga (Portugal).

61 Sobre este episodio ha escrito un campañero suyo. «Un buen día, por los alrededores de San José del año 1941, aterrizó en Veruela, un muchacho de Gerona, alto, bien plantado, de cabello rubio, corto y rizado, que andaba con paso fuerte haciendo tambalear aquellos pasadizos. Su mirada, a través de los cristales de las gafas, era a la vez tímida y alegre. Se llamaba Eusebi Colomer. Tenía una gran memoria y explicaba cosas y más cosas de historia con seguridad y precisión; los novicios le escuchaban con gusto; no tardó en ser muy popular» (Aragó Mitjans, J.M., S.I.P. Eusebi Colomer i Pous, S.I, Barcelona, 16 de diciembre de 1997, pp. 10-11).

62 Colomer, E., Nikolaus von Kues und Raimund Llull. Studien aus Handschrifften der Kueser Bibliothek, Berlín, Walter de Gruyter, 1961.

63 Torralba, F., «Colomer: el ejercicio de la sabiduría», en La Vanguardia, 7-XII-1997, p. 40. 
Estaba previsto que el día 3 de diciembre de 1997, a las 13 horas en la sede de la Facultad de Filosofía de Catalunya (URL) y de la Facultad de Teología de Catalunya se celebrará el Acto Académico de presentación de los dos últimos libros del Prof. Eusebio Colomer: El pensament als Països Catalans durant l'Edat Mitjana i el Renaixement y Movimientos de renovación: Humanismo y Renacimiento Intervendrían los profesores: Evangelista Vilanova, de la «Facultat de Teologia de Catalunya», Pere Lluís Font, de la «Facultat de Lletres» de la «Universitat Autònoma de Barcelona», y el autor de las dos obras.

El acto se celebró, aunque convirtiéndose en un homenaje a su memoria ${ }^{64}$ Estuvo presidido por el cardenal Carles, Arzobispo de Barcelona, que declaró que la noticia de la muerte repentina del profesor Colomer le había llegado cuando estaba leyendo su libro Movimientos de renovación. Humanismo y Renacimiento. Intervino también el Decano de la Facultad de Filosofía de la Universitat Ramon Llull, José M. Coll, que después de contar algunos datos de la vida personal del sabio jesuita catalán, como su gran afición a la ópera -recordaba de memoria varias óperas completas de Verdi, Wagner y Puccini-, indicó que Eusebi Colomer había hecho realidad el «pensar en diálogo», título de la miscelánea que le dedicó la Revista Catalana de Teología, en 1994, al jubilarse como profesor.

En otro artículo, el profesor Canals refería una conversación telefónica, que mantuvo con él menos de veinticuatro horas antes de su inesperada muerte, el día de la fiesta del franciscano beato Ramon Llull. Cuenta que: «La conversación se refería a la conveniencia de promover la declaración de san Ignacio de Loyola como doctor de la Iglesia. El P. Eusebi Colomer me respondió inmediatamente que encontraba muy fundamentada la posibilidad de que se llegase a esta declaración sobre el santo de los Ejercicios Espirituales. Me comentó que, después del doctorado de santa Teresa de Jesús, había quedado claro para todos que dicha declaración no se refería a una tarea (científica), sino a la excelencia de un don (carismático) en bien del pueblo cristiano». Añadió que: «También podría ser promovida, y sería plenamente fundamentada, la declaración como doctor de la Iglesia de san Francisco de Asís». ${ }^{65}$

Para terminar este pequeño escrito de homenaje agradecido a un gran maestro y excelente persona, nada mejor que citar las palabras de un artículo que apareció en la prensa barcelonesa, al día siguiente de su muerte. Su autor, el Dr. Josep M. ${ }^{a}$ Benítez i Riera, Decano de la Facultad de Historia de la Pontificia Universidad Gregoriana de Roma y Catedrático de Historia Moderna de esta universidad, comenzaba diciendo: «Ha muerto un hombre abierto a todo el mundo a través del interés por los filósofos de siempre, de todos los tiempos, y de su convicción de establecer siempre el diálogo. Nos dejó ayer, herido por un rápido y definitivo ataque de corazón [...] toda su vida ha sido un servicio magistral para hacer inteligible el pensamiento filosófico occidental».

64 Previamente se celebro una misa, en sufragio de su alma, en la capilla, presidida por el cardenal Carles. Los funerales habían tenido lugar el sábado, día 29 de noviembre de 1997, en el Centro Borja de Sant Cugat.

65 Canals Vidal, F., «El último don del padre Eusebi Colomer», en Catalunya Cristiana (Barcelona), 1-I-1998, p. 10. Ha escrito su compañero el profesor Joaquim M. ${ }^{2}$ Aragó Mitjans, S.I., sobre este aspecto de su personalidad: «Eusebi era un hombre de Dios, sinceramente piadoso y devoto. No es de extrañarse que encontrara tiempo para colaborar a lo largo de su vida en la parroaquia de la Sagarad Familia, y diera retiros y tandas de Ejercicios [...] También era un hombre de comunidad. Se encontraba bien en casa, y todos nos encontrabanos bien con él. Se podían tener deliciosos momentos de recreación, ya fuera para discutir de cosas serias o bien para bromear, bromas que el siempre acogía con una cierta ingenuidad y sencilla complacencia» (Aragó Mitjans, J.M., S.I.P. Eusebi Colomer i Pous, S.I, op. cit., p. 11). Deben destacarse también sus conversaciones filosóficas, siempre de gran altura, con su amigo y compañero el filósofo catalán Juan Pegueroles, S.I. 
Y finalizaba con estas palabras: «Ahora, que ha dejado este mundo, su magisterio de historiador de la filosofía pervivirá en sus obras, las escritas y las que obró haciendo el bien. Y sobre todo en la piadosa memoria de sus amigos», ${ }^{66}$ que somos muchísimos.

\author{
Eudaldo Forment \\ Facultad de Filosofía \\ Universidad de Barcelona \\ Baldiü Reixac, s/n \\ 08028 BARCELONA
}

66 Benítez I Riera, J.M., «Mor Eusebi Colomer, historiador de la filosofia», en Avui (Barcelona), 27-XI-1997, p. 3. Los textos originales en catalán son los siguientes: Ha mort un home obert a tot el món a través de l'interès pels filòsofs de sempre, de tots els temps, i de la seva convicció d'establir sempre diàleg. Ens va deixar ahir, colpitt per un ràpid i defginitiu atac de cor [...] tota la seva vida ha estat un servei magistral per fer intel.ligible el pensament filosòfic occidental». «Ara, que ha deixat aquest món, el seu magisteri d'historiador de la filosofia perviurà en les seves obres, les escrites i les que obrà fente el be. I sobretot en la pietosa memòria del seus amic». 